\title{
Prospective Randomized Study Comparing Concomitant Chemoradiotherapy Using Three Weekly Cisplatin and Biweekly 5-Fluorouracil versus Weekly Paclitaxel in Locally Advanced Carcinoma Cervix
}

\author{
Sapna Marcus ${ }^{1}$ Jasmeet Kaur ${ }^{2}$ Hanuman Prasad Yadav \\ ${ }^{1}$ Department of Radiation Oncology, Crown Princess Mary Cancer \\ Center, Sydney, Australia \\ 2Department of Radiation Oncology, GGS Medical College and \\ Hospital, Faridkot, Punjab, India \\ ${ }^{3}$ Department of Radiation Oncology, Institute of Liver and Biliary \\ Sciences, New Delhi, India
}

\begin{abstract}
Address for correspondence Sapna Marcus, MD, DNB, Department of Radiation Oncology, Crown Princess Mary Cancer Center, Westmead Hospital, Sydney, NSW, Australia (e-mail: sapnamarcus@gmail.com).
\end{abstract}

Asian J Oncol 2018;4:54-60

\begin{abstract}
India being the second most populous country in the world accounted for $25 \%$ of cervical cancer death according to GLOBOCAN 2012. Although there are many agents available, the need for a model chemotherapy regimen that is effective and at the same time less toxic and has easy affordability is the current unmet need. We devised a study with the most commonly available and affordable drugs such as Cisplatin, 5-Fluorouracil (5FU), and Paclitaxel. The main objective was to study the efficacy of concurrent chemoradiotherapy in treatment of carcinoma cervix, using two different regimens in terms of clinical response evidenced clinically as well as on imaging. Secondary objectives were to assess the progression-free and overall survival. It was clearly evident that the response rate could be appreciated clinically in arm B over A; however, this difference could not be justified by statistical methods. Tox-

Keywords

- 5-fluorouracil

- carcinoma cervix

- cisplatin

- overall survival

- progression-free survival icities observed in both the arms was comparable, and in terms of progression-free and overall survival, the differences were not significant suggesting that the both the options could be considered in the treatment. Although the outcome looks promising prompting exploration of more such combinations that are easily available in the rural hospitals, but because of smaller sample size and smaller follow-up, a multi-institutional study with a larger sample size and a longer follow-up is definitely required to set the ball rolling in favor of combination chemotherapy, including cisplatin and 5FU.
\end{abstract}

\section{Introduction}

In 2012, according to GLOBOCAN, there were 527,600 new cervical cancer cases and 265,700 deaths reported worldwide. ${ }^{1}$ Majority of global burden occurs in the less developed regions, where it amounts for $12 \%$ of all gynecologic cancers. Carcinoma cervix is the most common female malignancy in India with crude incidence rate of 23.5 per 100,000 women per year, and of the estimated 134,420 new cases every year, 72,825 women will die partially due to inadequacy of the current treatment..-4
Radiotherapy is the mainstay of treatment for locally advanced cervical cancer. The ability of radiotherapy to cure locally advanced cervical cancer is limited by the tumor size because the doses required to treat large tumors exceeds the limit of radiation tolerance in normal tissue. Based on multicentric trials favoring chemoradiation compared with radiation alone for improved overall survival (OS) and reducing local and distant recurrence suggesting concomitant chemotherapy, the National Cancer Institute issued a clinical alert stating that "strong consideration should be given to the incorporation of concurrent
License terms

() (1) $\ominus \circledast$ 
cisplatin-based chemotherapy with radiation in women who require radiation therapy in cervical cancer." ${ }^{5}$

The reigning position of platinum agents in the treatment of advanced cervical cancer was questioned by the analysis of the Cochrane Collaboration meta-analysis in 2010, which showed that the benefit observed in previous concurrent chemoradiotherapy-based randomized trials may not depend on the use of platinum only. ${ }^{6} \mathrm{~A}$ randomized study by Christie et al confirmed that the addition of 5-Fluorouracil (5FU) to radiotherapy increased survival and local control. ${ }^{7}$ However, the role of 5FU, as a radio-sensitizing agent, is still severely underexploited; therefore, further research and trials are required on a broader scale for its role to be stated as a chemotherapeutic agent used in treatment of carcinoma cervix in a concurrent setting.

On the other hand, the role of taxanes has emerged recently in cervical cancer. Paclitaxel is a taxane-based alkaloid from pacific yew (Taxus brevifolia) ${ }^{8}$ that inhibits tubular aggregation. ${ }^{9,10}$ Paclitaxel was found to have significant activity in solid tumors, especially epithelial ovarian, lung, and breast cancer. ${ }^{12}$ Preclinical studies have shown a radio-sensitizing effect of paclitaxel in human cervical cancer cell lines. ${ }^{13} \mathrm{Com}-$ bination of cisplatin and paclitaxel has been used in metastatic or recurrent carcinoma of the cervix in various phases II and III trials with an objective response rate of 36 to $46 \%$. It was affirmed by these trials ${ }^{11,14-16}$ that concomitant administration of cisplatin and paclitaxel was more effective than cisplatin alone in relapsed cases of advanced cervical cancer.

These facts have led many groups to investigate other drugs such as paclitaxel in an attempt to improve on what can be achieved by cisplatin alone. However, little evidence is there to prove that paclitaxel increases the overall response as compared with cisplatin..$^{17,18}$ However, in a rural Indian setting where the standard treatment needs to be optimized with the primary drugs such as cisplatin, 5FU, and paclitaxel, it becomes imperative to devise an optimal regimen that can be used in a concomitant setting with radiotherapy to achieve maximum tumor control with minimum toxicity. This would not only improve compliance to the treatment owing to the less toxicity but also lead to improved OS and quality of life.

\section{Materials and Methods}

This was a 1-year randomized prospective study, including 60 histologically proven patients with carcinoma of the cervix in a tertiary cancer institute in a rural Indian setting. The main objective of this study was to assess the efficacy of two different regimens of concurrent chemoradiotherapy in a concurrent setting in treatment of carcinoma of the cervix in terms of compliance to treatment, toxicities, and progression-free survival (PFS).

Patients were randomized into two different arms using central computed randomization technique $(\boldsymbol{- F i g}$. $\mathbf{1})$. The study arms were divided into arm A including patients receiving concurrent chemoradiotherapy with weekly paclitaxel $\left(60 \mathrm{mg} / \mathrm{m}^{2}\right)$ and arm B who received concurrent chemoradiotherapy with 3 weekly cisplatin $\left(50 \mathrm{mg} / \mathrm{m}^{2}\right)$ and biweekly $5 \mathrm{FU}\left(500 \mathrm{mg} / \mathrm{m}^{2}\right)$. There were 29 patients in arm A and 31 patients in arm B. Both the chemotherapy schedules were studied along with concurrent radiotherapy in terms of PFS, OS, and toxicities.

\section{Inclusion Criteria}

- Age $<70$ years.

- European Cooperative Oncology Group (ECOG) performance scale of 1 or 2

- Biopsy-proven carcinoma of the cervix.

- Stage IIB-IVA carcinoma of the cervix. Staging will be done as per International Federation of Gynecology and Obstetrics (FIGO) staging 2009.

- Normal hematologic, renal, and hepatic functions profile.

- No prior chemotherapy or radiotherapy received.

- Signed written consent as per institutional regulation.

\section{Exclusion Criteria}

- Patients who have received chemotherapy or radiotherapy prior to this study will be excluded from the study.

- Patients not fulfilling the inclusion criteria are excluded from the study.

A dose of 5,000 cGy in 25 fractions over 5 weeks was given by external beam radiotherapy (EBRT) either by two or four fields, during which patients' weekly assessment was done. After 1 week of completion of EBRT, patients were assessed for brachytherapy and those appropriate were taken up for the treatment. Patients were reassessed for clinical response using the Response Evaluation Criteria in Solid Tumors (RECIST) (version 1.1) criteria. Radiation Therapy Oncology Group (RTOG) toxicity criteria were used to access radiation-induced toxicities. Patients were assessed by magnetic resonance imaging (MRI) at the end of treatment and thereafter at 6 weeks and at 6 months for disease response and were categorized in following groups accordingly:

Complete responders: Complete regression of lesion.

Partial responders: > 50\% regression in lesion in maximum diameter.

No responders: Lesion regressed $<50 \%$ in maximum diameter.

During statistical analysis of the findings, we used SPSS (Statistical Package for Social Sciences) version 17 (Chicago, IL, United States). We also analyzed the data using cross-tables and checked the significance using chi-square test for different variables. For assessing the PFS and OS, we used the Kaplan-Meier curves.

The strengths of this study were that it compared two schedules of chemotherapy, which have not been explored before in a head on trial setting along with concomitant radiotherapy. A different dosing schedule that was considered less toxic and more manageable as well as treatment compliant was adopted. The other favorable aspect of our study was that the drugs chosen for the study has already demonstrated efficacy as first-line drugs in treatment of carcinoma cervix and also had easy availability on a regular basis in a rural setting. The other most important strength 


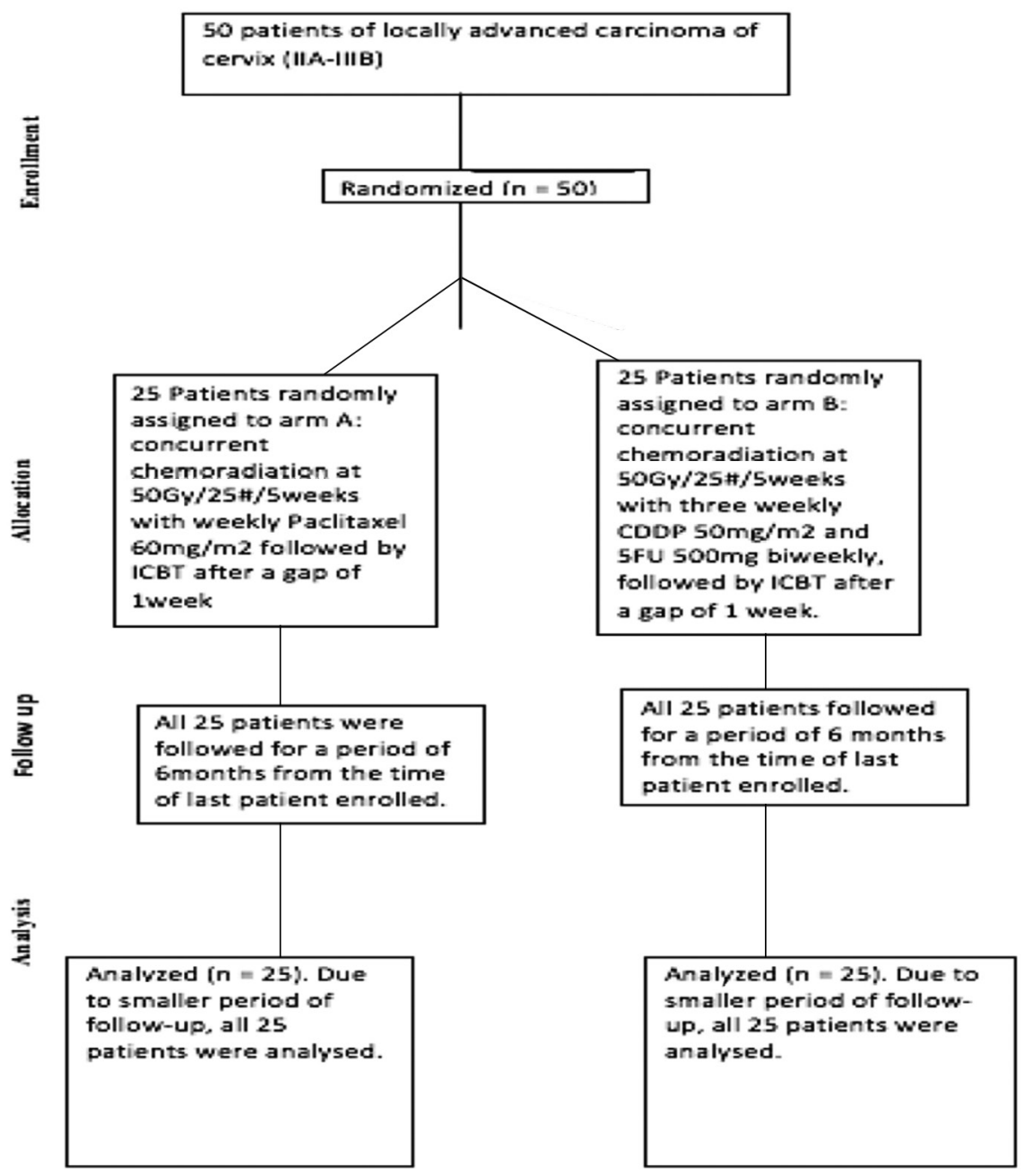

Fig. 1 Consort diagram depicting distribution of patients.

of this study was that the drugs used in the study were acceptable in terms of affordability, which has always been a limiting step in similar studies due to lack of any financial support from the institution or any medical companies. At the same time, the drawbacks of the study were the small size of the study, as well as its limited follow-up period due to its time-bound nature. Nevertheless, the results can always be reassessed after a longer follow-up for concrete analysis. We recommend that a long-term follow-up should be performed to remove confounding factors and provide authenticity to the study.

\section{Results and Analysis}

At the time of analysis of the results, two patients were lost to follow-up in arms A and B. In addition to this, in arm B, one patient was started on a different regimen due to intolerance to chemotherapeutic agent and one died during the treatment, leaving a total of 27 patients in each arm.

1. Patients in both the study groups were comparable regarding age distribution. The mean age $\pm \mathrm{SD}$ (standard deviation) in arm A was $51.41 \pm 9.544$ years and in B was $48.85 \pm 10.007$ years. In our study, $60 \%$ of patients were in fourth and fifth decades.
2. Thirteen (48.1\%) patients in arm A and 17 (63\%) in arm $B$ had ECOG PS of 1 at presentation, whereas 14 (51.9\%) patients in arm A and 10 (37\%) in arm B had ECOG PS of 2.

3. The most common histopathology was squamous cell variety found in 53 (98.15\%) patients, followed by its variants in 1 (1.25\%) patient. There were no cases of adenocarcinoma detected.

4. The distribution of patients according to stage at presentation is documented in - Table $\mathbf{1}$.

\section{Treatment Profile}

All patients in the respective arms received radiotherapy with a combined dose of 80 to $85 \mathrm{~Gy}$, delivered by EBRT and BRT. Patients in arm A received concurrent chemotherapy with weekly paclitaxel whereas those in arm B received concurrent chemotherapy with 3 weekly cisplatin and biweekly $5 \mathrm{FU}$.

5. It was evident that 17 (63\%) patients, less than two-third of the patients, completed five cycles (desired number) of weekly paclitaxel in arm A. However, in arm B, more than two-thirds of the patients, that is, 24 (88.9\%) patients, completed more than two cycles (desired number) of cisplatin and approximately 18 (66.7\%) patients completed more than seven to eight cycles of planned 
5FU regimen. Overall treatment delay was observed in a total of $22(40.74 \%)$ patients. This difference of treatment time delay in both the groups was not statistically significant $(p=0.857)$.

\section{Toxicity Profile}

6. - Tables 2-4 show that incidence of treatment-related gastrointestinal (GI) toxicity. Most patients in both the groups did not show symptoms of toxicity during first week of treatment. Most toxicities occurred beyond second week and were grade 2 irrespective of the chemotherapy agents used. The difference between the toxicities was not statistically significant $(p=0.233$ ).

7. While on the acute hematologic toxicity front, both the arms exhibited an uneventful first week, followed by grade 1 toxicity during the second week. From third week onward, as expected, the toxicity increased but more so in arm A than in B. During fourth week of treatment, almost all patients had grade 1 toxicity. The difference between the toxicity levels in both the arms was not statistically significant $(p=0.836)$. During fifth week of treatment, only two (7.4\%) patients exhibited grade 3 toxicity, belonging to arm $B$.

8. In the case of chemotherapy-induced neutropenia, it was evident that most patients in both the arms had grade 1 toxicity, but the percentage of patients having grade 2 toxicity increased especially in arm A during the course

Table 1 Distribution of patients according to FIGO stage

\begin{tabular}{|l|l|l|l|}
\hline $\begin{array}{l}\text { FIGO } \\
\text { stage }\end{array}$ & $\begin{array}{l}\text { Patients in } \\
\text { arm } A, \boldsymbol{n}(\%)\end{array}$ & $\begin{array}{l}\text { Patients in } \\
\text { arm B, } \boldsymbol{n}(\%)\end{array}$ & $\begin{array}{l}\text { Total number of } \\
\text { patients, } \boldsymbol{n}(\%)\end{array}$ \\
\hline 2B & $11(40.7)$ & $11(40.7)$ & $22(40.7)$ \\
\hline 3A & $3(11.1)$ & $1(3.7)$ & $4(7.4)$ \\
\hline 3B & $11(40.7)$ & $12(44.4)$ & $23(42.6)$ \\
\hline 4A & $2(7.4)$ & $3(11.1)$ & $5(9.3)$ \\
\hline Total & $27(100)$ & $27(100)$ & $54(100)$ \\
\hline
\end{tabular}

Abbreviation: FIGO, International Federation of Gynecology and Obstetrics.

Distribution of patients according to the disease stage (Staging according to FIGO 2009.)

Table 3 Distribution of patients according to tumor response at 6 weeks of completion of treatment

\begin{tabular}{|l|l|l|l|}
\hline $\begin{array}{l}\text { Response } \\
\text { at } \mathbf{6} \mathbf{w k}\end{array}$ & $\begin{array}{l}\text { Arm A, } \\
\boldsymbol{n}(\%)\end{array}$ & Arm B, $\boldsymbol{n}(\%)$ & $\begin{array}{l}\text { Total number of } \\
\text { patients, } \boldsymbol{n}(\%)\end{array}$ \\
\hline CR & $19(70.4)$ & $24(88.9)$ & $43(79.6)$ \\
\hline PR & $8(29.6)$ & $2(7.4)$ & $10(18.5)$ \\
\hline PD & 0 & 0 & 0 \\
\hline SD & 0 & 0 & 0 \\
\hline Died & 0 & $1(3.7)$ & $1(1.9)$ \\
\hline Total & $27(100)$ & $27(100)$ & $27(100)$ \\
\hline
\end{tabular}

Abbreviations: $C R$, complete response; PD, progressive disease; $P R$, partial response; SD, stable disease.

Distribution of patients according to tumor response at 6 weeks of treatment. of the treatment. During the entire treatment, none of the patient progressed to grade 3 or 4 toxicity. The difference was statistically nonsignificant $(p=0.217)$.

9. Representation of patients requiring hospital admission for the management of chemotherapy-related toxicities in both the arms is tabulated in - Fig. 2 .

\section{Tumor Response}

Tumor response was assessed clinically with MRI at completion of treatment, at 6 weeks, and subsequently at 6 months of treatment completion.

10. - Tables 2-4 show that 19 (70.4\%) patients in arm $A$ and 23 (85.2\%) in arm $B$ had complete response at the completion of treatment (2A). The findings were consistent at 6 weeks and 6 months of treatment with 19 (70.4\%) patients in arm A and 24 (88.9\%) in arm B showing complete response (Tables 3, 4). Of patients showing partial response there were eight (29.6\%) patients in arm A and three (11.1\%) in arm B at treatment completion. The results were consistent at successive assessments. There is a difference of 18\% in response rate in both the arms, which was appreciated clinically at 6 months; however, this difference is not statistically significant $(p=0.362)$ and therefore needs a larger sample size and a longer follow-up for validating our study.

Table 2 Distribution of patients according to tumor response at completion of treatment

\begin{tabular}{|l|l|l|l|}
\hline Response & $\begin{array}{l}\text { Arm A, } \\
\boldsymbol{n}(\%)\end{array}$ & Arm B, $\boldsymbol{n}(\%)$ & $\begin{array}{l}\text { Total number of } \\
\text { patients, } \boldsymbol{n}(\%)\end{array}$ \\
\hline CR & $19(70.4)$ & $23(85.2)$ & $42(77.8)$ \\
\hline PR & $8(29.6)$ & $3(11.1)$ & $11(20.4)$ \\
\hline PD & 0 & 0 & 0 \\
\hline SD & 0 & 0 & 0 \\
\hline Died & 0 & $1(3.7)$ & $1(1.9)$ \\
\hline Total & $27(100)$ & $27(100)$ & $54(100)$ \\
\hline
\end{tabular}

Abbreviations: CR, complete response; PD, progressive disease; $P R$, partial response; SD, stable disease.

Distribution of patients according to tumor response at completion of treatment.

Table 4 Distribution of patients according to tumor response at 6 months of completion of treatment

\begin{tabular}{|l|l|l|l|}
\hline $\begin{array}{l}\text { Response } \\
\text { at } 6 \text { mo }\end{array}$ & $\begin{array}{l}\text { Arm A, } \\
\boldsymbol{n}(\%)\end{array}$ & $\begin{array}{l}\text { Arm B, } \\
\boldsymbol{n}(\%)\end{array}$ & $\begin{array}{l}\text { Total number of } \\
\text { patients, } \boldsymbol{n}(\%)\end{array}$ \\
\hline CR & $19(70.4)$ & $24(88.9)$ & $43(79.6)$ \\
\hline PR & $1(3.7)$ & 0 & $1(1.9)$ \\
\hline PD & $5(18.5)$ & $2(7.4)$ & $7(13)$ \\
\hline SD & 0 & 0 & 0 \\
\hline Died & $2(7.4$ & $1(3.7)$ & $3(5.5)$ \\
\hline Total & $27(100$ & $27(100)$ & $54(100)$ \\
\hline
\end{tabular}

Abbreviations: $C R$, complete response; $P D$, progressive disease; $P R$, partial response; SD, stable disease.

Distribution of patients according to tumor response at 6 months of completion of treatment. 
11. Patients' overall status was assessed from enrollment of the first patient till the last follow-up (-Table 5 ). Patients enrolled during initial period of study had longer follow-up than those enrolled in later period of study. Patients' overall status observed at 6 to 8 months and beyond 8 months was almost equal in both the arms. It was clear that the incidence of residual disease was appreciably high in $\operatorname{arm} \mathrm{A}$, almost double to that of arm B. Also, the deceased patients in arm A were twice in number to that in arm $B$.

12. In terms of PFS and OS, there was no significant difference among the two arms $(p>0.05)$. The survival graph curve of arm B ( - Fig. 3 ) is fairly better than that

Table 5 Distribution of patients according to PFS at 6 months of follow-up

\begin{tabular}{|l|l|l|l|l|}
\hline $\begin{array}{l}\text { PFS } \\
(\mathrm{mo})\end{array}$ & $\begin{array}{l}\text { Arm A, } \\
\boldsymbol{n}(\%)\end{array}$ & $\begin{array}{l}\text { Arm B, } \\
\boldsymbol{n}(\%)\end{array}$ & $\begin{array}{l}\text { Total number } \\
\text { of patients, } \\
\boldsymbol{n}(\%)\end{array}$ & $p$-Value \\
\hline$<6$ & $2(7.4)$ & $2(7.4)$ & $4(7.4)$ & 0.341 \\
\hline $6-8$ & $9(33.3)$ & $7(26)$ & $16(29.6)$ & \\
\hline$>8$ & $16(59.3)$ & $18(66.6)$ & $34(63)$ & \\
\hline Total & $27(100)$ & $27(100)$ & $54(100)$ & \\
\hline $\begin{array}{l}\text { Mean } \\
\pm \text { SD }\end{array}$ & $\begin{array}{l}10.15 \pm \\
3.708\end{array}$ & $\begin{array}{l}11.15 \pm \\
3.929\end{array}$ & & \\
\hline Median & 10 & 11 & & \\
\hline
\end{tabular}

Abbreviations: PFS, progression-free survival; SD, standard deviation. Distribution of patients according to PFS till 6 months of follow-up of the last patient enrolled in the study arms. of arm A. However, as seen in our study, at some or the other point both curves interchange, so one group is better for some period of time, and at other point, the other group crosses it. In PFS, however, arm B is slightly better but not significantly. Also, we can see mean survival time graph that the arm B is better than $A$.

\section{Discussion}

To reach to an academic consensus on the standard chemotherapy schedule, amidst the wide range of options available is a gigantic task in itself. The optimal choice of chemotherapy is still a gray zone in terms of carcinoma of the cervix with its varied sensitivity to variable drugs. Therefore, this study was undertaken to throw new light on the possible combinations of the most common and easily available drugs in the rural settings of Northern India, which might prove to be more acceptable leading to increased compliance of the treatment.

The most common reasons for local recurrence have been attributed to incomplete treatments that in turn are caused mostly due to chemotherapy-induced toxicities and increased overall treatment time (OTT). Patients receiving chemoradiation have increased treatment-related toxicities as compared with those receiving radiation alone. Among them, the most common are nausea, enteritis, and hematologic toxicities. The most common reason for failure to complete chemotherapy as expected was GI toxicity. There was no correlation between failure to complete planned chemotherapy and patient age, disease stage, radiotherapy treatment volumes, or postoperative treatment. ${ }^{19}$ In a study

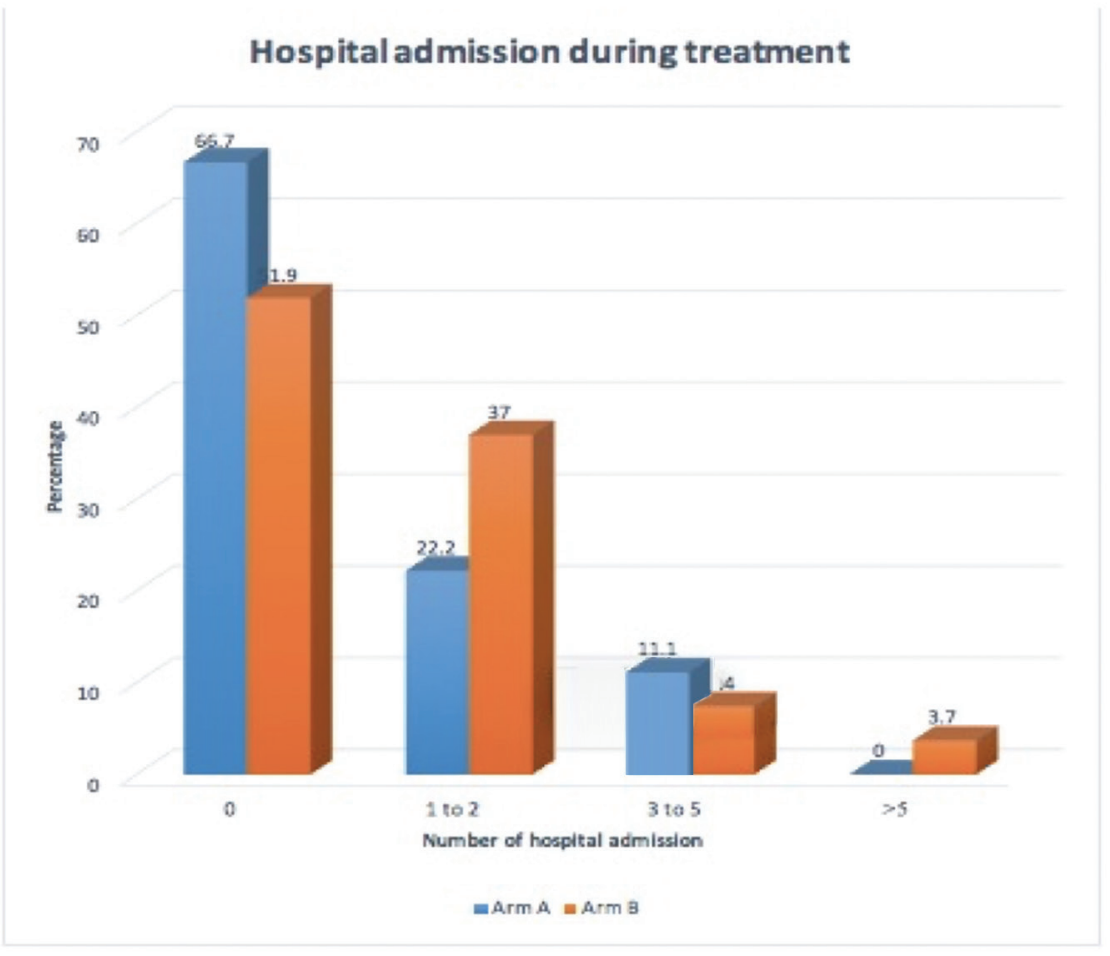

Fig. 2 Representation of patients according to number of hospital admissions required during treatment. 


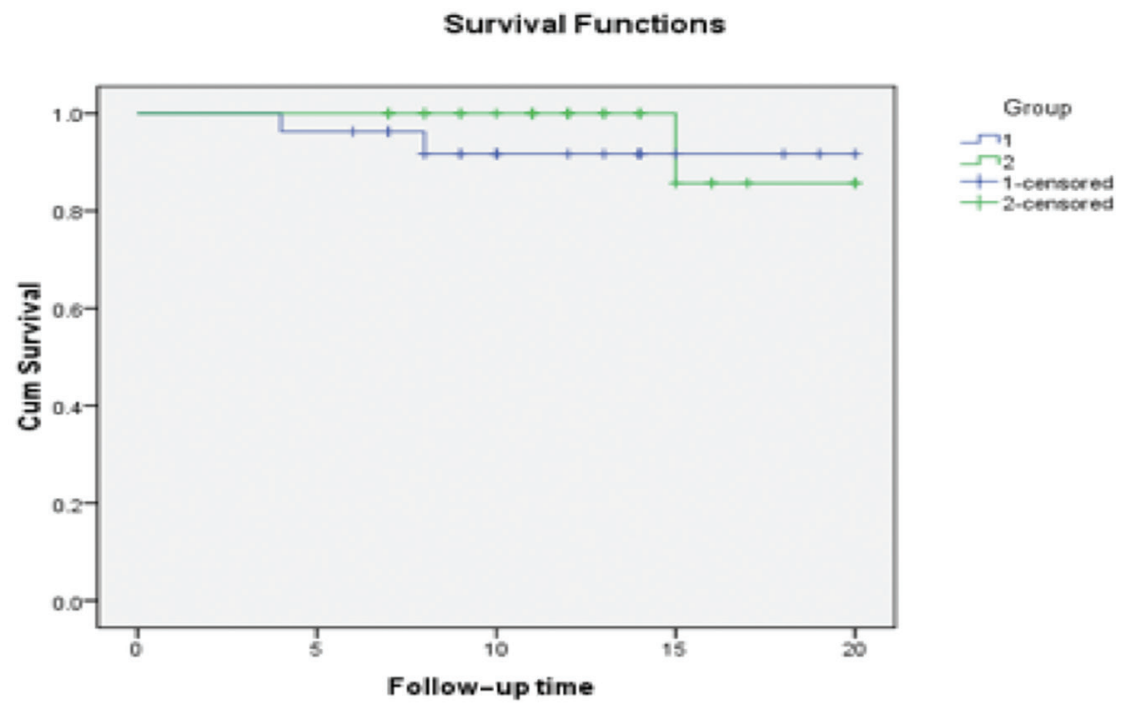

An interchangeable pattern was seen suggesting arm $B$ to be superior in the initial phase whereas arm $A$ to be superior in the latter phase.

Fig. 3 Survival functions of both study arms.

by Jakubowicz et al, acute treatment-related toxicity grade 3 or 4 (World Health Organization [WHO]) occurred in $21.6 \%$ of patients including leucopoenia in $7.5 \%$, anemia in $5 \%$, nausea and vomiting in 3.3\%, diarrhea in 5\%, and urinary tract infection in $0.8 \% .^{20}$ In our study, a total of $97.3 \%$ of patients completed treatment without any interruptions for treatment-related toxicity. Only two (3.4\%) patients experienced a delay in brachytherapy for treatment-related toxicity. The common toxicities observed in our study were GI and hematologic. However, this difference in the toxicities between the two chemoradiation groups was not statistically significant ( $p=0.440$ ), irrespective of a combination chemotherapeutic schedule adopted in arm B. To emphasize, toxicities in both the arms were at an acceptable level, thereby offering an affordable. The other reason for increased recurrence rate is OTT. Median OTT of 8 weeks is considered optimal by various investigators. ${ }^{21,22}$ In our study, 17 (63\%) patients in arm A, and 18 (66.7\%) in arm B, which amounts to more than two-thirds of the target population, completed their prescribed treatment in the desired time frame of 8 to 9 weeks. The mean treatment duration in both the study arms was 60 to 68 days, which was longer than the standard accepted time period. The reasons behind this was that ours was a tertiary care setup. With an ongoing academic program, many patients receiving treatment were from rural areas with compromised nutritional status and therefore required time for nutritional buildup or toxicity management. Also, most patients were from low socioeconomic status and uneducated, thereby undermining the importance of treatment.

In the study, clinical response assessed at completion of treatment confirmed that there was a difference of $18 \%$ in the response rate between two arms favoring arm B; however, this difference was not statistically significant $(p=0.161)$. The clinical response attained at 6 weeks of treatment completion and at 6 months of follow-up was consistent. Stehman et $\mathrm{al}^{23}$ in their study with concurrent chemoradiotherapy with cisplatin and 5FU, observed complete disappearance of all clinical evidence of disease in 65 (86.7\%) of patients, with the complete response and partial response rate of $93.3 \%$. The findings were affirmed with our study results with arm B containing 5FU and cisplatin regimen showing complete response rate of $88.9 \%$ and partial response rate of $95 \%$. Whereas in defense for arm A, sufficient evidence was gathered by Umayahara et al, who in their study observed concurrent chemoradiation with weekly paclitaxel and cisplatin showing complete response in $85 \%$ patients. ${ }^{24}$ However, in our study, 70\% complete response was seen in weekly paclitaxel arm. The reasons attributed for the slope in response rate could be because a single drug was used.

PFS and OS were also comparable in both the arms. The Kaplan-Meier graph curves demonstrated an early survival advantage with arm B initially, but in the latter part of the study, arm A took over and both the survival curves remained interchangeable during the study period. However, in our study, the main limitation was a relatively small sample size, which could be due to single institution study. Because of the study being conducted in a time-bound manner, enrolment was conducted for 1 year only. Further, because of the advanced-stage presentation and poor nutritional status, approximately $18 \%$ patients did not have adequate regression of the disease at the completion of EBRT and therefore could not be included for brachytherapy. The answers to this problem lie in conducting more multi-institutional trials to overcome the problem of small sample size. The incorporation of positron-emission tomography-based response-evaluation 
criteria (PERCIST) may improve accuracy of response assessment.

Therefore, the results in both the studies reaffirmed that concomitant chemoradiotherapy is the answer to locally advanced cervical carcinoma. There have been many chemotherapeutic agents that boast of high efficacy against the malignancy along with added radiosensiti zing property, which are unfortunately not readily available or affordable at cancer centers in rural areas. However, there is still a persistent gray zone that needs reexploration at every angle, especially when it comes to a rural setup with limited resources.

The results observed were definitely in favor of the arm including cisplatin and 5FU showing clinically appreciable complete response rate and also decreased progressive disease. However, the results cannot be validated on concrete grounds, as of now due to study limitations. Therefore, based on these results, we can conclude that this study very efficiently opens new horizons in terms of newer schedules of the commonly available chemotherapeutic agents that can be exploited with different dosing and schedules to offer treatment benefits to patients with advanced cervical carcinoma where treatment-related toxicities and OTT delay pose a major problem in attaining complete response due to poor performance status of patients hailing from rural backgrounds.

\section{Funding}

None declared.

\section{Conflict of Interest}

None declared.

\section{References}

1 Ferlay J, Soerjomataram I, Dikshit R, et al. Cancer incidence and mortality worldwide: sources, methods and major patterns in GLOBOCAN 2012. Int J Cancer 2015;136(5):E359-E386

2 WHO/ICO Information Centre on HPV and Cervical Cancer (HPV Information Centre). Human Papillomavirus and Related Cancers in World. Summary Report; 2010. Available at: www. who. int/ hpvcentre. Accessed January 15, 2011

3 Sankaranarayanan R, Nene BM, Dinshaw K, et al. Early detection of cervical cancer with visual inspection methods: a summary of completed and on-going studies in India. Salud Publica Mex 2003;45(Suppl 3):S399-S407

4 Shukla S, Bharti AC, Mahata S, et al. Infection of human papillomaviruses in cancers of different human organ sites. Indian J Med Res 2009;130(3):222-233

5 National Cancer Institute. Concurrent Chemotherapy for Cervical Cancer: Clinical Announcement. Washington, DC: National Cancer Institute; 1999

6 Chemoradiotherapy for Cervical Cancer Meta-analysis Collaboration (CCCMAC). Reducing uncertainties about the effects of chemoradiotherapy for cervical cancer: individual patient data meta-analysis. Cochrane Database Syst Rev 2010;(1):CD008285

7 Christie DR, Bull CA, Gebski V, Langlands AO. Concurrent 5-fluorouracil, mitomycin C and irradiation in locally advanced cervix cancer. Radiother Oncol 1995;37(3):181-189

8 Wall ME, Wani MC. Paclitaxel from discovery to clinic. In: George GI, Chen TT, Ojima I, eds. Taxane Anticancer Agent
Basic Sciences and Current Status. Vol. 2. Washington, DC: American Chemical Society; 1995:18-30

9 Schiff PB, Fant J, Horwitz SB. Promotion of microtubule assembly in vitro by taxol. Nature 1979;277(5698):665-667

10 Pazdur R, Kudelka AP, Kavanagh JJ, Cohen PR, Raber MN. The toxoids: paclitaxel (Taxol) and docetaxel (Taxotere). Cancer Treat Rev 1993;19(4):351-386

11 Curtin JP, Blessing JA, Webster KD, et al. Paclitaxel, an active agent in nonsquamous carcinomas of the uterine cervix: a Gynecologic Oncology Group Study. J Clin Oncol 2001;19(5):1275-1278

12 Geara FB, Shamseddine A, Khalil A, Abboud M, Charafeddine M, Seoud M. A phase II randomized trial comparing radiotherapy with concurrent weekly cisplatin or weekly paclitaxel in patients with advanced cervical cancer. Radiat Oncol 2010;5:84

13 Pradier O, Rave-Fränk M, Schmidberger H, et al. Effects of paclitaxel in combination with radiation on human head and neck cancer cells (ZMK-1), cervical squamous cell carcinoma (CaSki), and breast adenocarcinoma cells (MCF-7). J Cancer Res Clin Oncol 1999;125(1):20-27

14 Papadimitriou CA, Sarris K, Moulopoulos LA, et al. Phase II trial of paclitaxel and cisplatin in metastatic and recurrent carcinoma of the uterine cervix. J Clin Oncol 1999;17(3):761-766

15 Rose PG, Blessing JA, Gershenson DM, McGehee R. Paclitaxel and cisplatin as first-line therapy in recurrent or advanced squamous cell carcinoma of the cervix: a gynecologic oncology group study. J Clin Oncol 1999;17(9):2676-2680

16 Moore DH, Blessing JA, McQuellon RP, et al. Phase III study of cisplatin with or without paclitaxel in stage IVB, recurrent, or persistent squamous cell carcinoma of the cervix: a gynecologic oncology group study. J Clin Oncol 2004;22(15):3113-3119

17 Varghese SS, Ram TS, Pavamani SP, Thomas EM, Jeyaseelan V, Viswanathan PN. Concurrent chemo-irradiation with weekly cisplatin and paclitaxel in the treatment of locally advanced squamous cell carcinoma of cervix: a phase II study. J Cancer Res Ther 2014;10(2):330-336

18 Thakur P, Seam R, Gupta M, Gupta M. Prospective randomized study comparing concomitant chemoradiotherapy using weekly cisplatin \& paclitaxel versus weekly cisplatin in locally advanced carcinoma cervix. Ann Transl Med 2016;4(3):48

19 Tan LT, Russell S, Burgess L. Acute toxicity of chemoradiotherapy for cervical cancer: the Addenbrooke's experience. Clin Oncol (R Coll Radiol) 2004;16(4):255-260

20 Jakubowicz J, Blecharz P, Skotnicki P, Reinfuss M, Walasek T, Luczynska E. Toxicity of concurrent chemoradiotherapy for locally advanced cervical cancer. Eur J Gynaecol Oncol 2014;35(4):393-399

21 Fyles A, Keane TJ, Barton M, Simm J. The effect of treatment duration in the local control of cervix cancer. Radiother Oncol 1992;25(4):273-279

22 Lanciano RM, Pajak TF, Martz K, Hanks GE. The influence of treatment time on outcome for squamous cell cancer of the uterine cervix treated with radiation: a patterns-of-care study. Int J Radiat Oncol Biol Phys 1993;25(3):391-397

23 Stehman FB, Bundy BN, Kucera PR, Deppe G, Reddy S, O'Connor DM. Hydroxyurea, 5-fluorouracil infusion, and cisplatin adjunct to radiation therapy in cervical carcinoma: a phase I-II trial of the Gynecologic Oncology Group. Gynecol Oncol 1997;66(2):262-267

24 Umayahara K, Takeshima N, Nose T, et al. Phase I study of concurrent chemoradiotherapy with weekly cisplatin and paclitaxel chemotherapy for locally advanced cervical carcinoma in Japanese women. Int $\mathrm{J}$ Gynecol Cancer 2009;19(4):723-727 